\title{
Article \\ Effect of the Location of Strut Chordae Insertion on Computational Modeling and Biomechanical Evaluation of Mitral Valve Dynamics
}

\author{
Woojae Hong, Soohwan Jeong, Minsung Ko, Hyun Hak Kim and Hyunggun Kim * \\ Department of Biomechatronic Engineering, Sungkyunkwan University, Suwon 16419, Korea; \\ woojaehong94@gmail.com (W.H.); jeongsoohwan92@gmail.com (S.J.); minsungko413@gmail.com (M.K.); \\ kim.hyun.hak95@gmail.com (H.H.K.) \\ * Correspondence: hkim.bme@skku.edu; Tel.: +82-31-290-7821
}

check for

updates

Citation: Hong, W.; Jeong, S.; Ko, M.; Kim, H.H.; Kim, H. Effect of the Location of Strut Chordae Insertion on Computational Modeling and Biomechanical Evaluation of Mitral Valve Dynamics. Appl. Sci. 2021, 11, 6205. https://doi.org/10.3390/ app11136205

Academic Editors: Joung Hwan Mun and Hanatsu Nagano

Received: 30 April 2021

Accepted: 28 June 2021

Published: 5 July 2021

Publisher's Note: MDPI stays neutral with regard to jurisdictional claims in published maps and institutional affiliations.

Copyright: (c) 2021 by the authors. Licensee MDPI, Basel, Switzerland. This article is an open access article distributed under the terms and conditions of the Creative Commons Attribution (CC BY) license (https:/ / creativecommons.org/licenses/by/ $4.0 /)$.

\begin{abstract}
The strut chordae (SC) have a unique structure and play an important role in reinforcing the tunnel-shaped configuration of the mitral valve (MV) at the inflow and outflow tracts. We investigated the effect of varying the SC insertion location on normal MV function and dynamics to better understand the complex MV structures. A virtual parametric MV model was designed to replicate a normal human $\mathrm{MV}$, and a total of nine $\mathrm{MV}$ modes were created from combinations of apical and lateral displacements of the SC insertion location. MV function throughout the full cardiac cycle was simulated using dynamic finite element analysis for all MV models. While the leaflet stress distribution and coaptation showed similar patterns in all nine MV models, the maximum leaflet stress values increased in proportion to the width of the SC insertion locations. A narrower SC insertion location resulted in a longer coaptation length and a smaller anterior coaptation angle. The top-narrow MV model demonstrated the shortest anterior leaflet bulging distance, lower stresses across the anterior leaflet, and the lowest maximum stresses. This biomechanical evaluation strategy can help us better understand the effect of the SC insertion locations on mechanism, function, and pathophysiology of the MV.
\end{abstract}

Keywords: mitral valve; strut chordae; strut chordae insertion location; finite element; computational simulation

\section{Introduction}

An intricate tissue structure, the mitral valve (MV), regulates blood flow between the left atrium and the left ventricle (LV), and the components of the MV apparatus play complex roles to properly maintain normal MV function. The MV apparatus is composed of the mitral annulus, two (anterior and posterior) leaflets, chordae tendineae, and papillary muscles. While LV pressure increases during systole, the circumferential size of the mitral annulus decreases. This facilitates leaflet contact and closes the mitral orifice. The papillary muscles contract and hold the chordae tendineae to prevent the leaflets from prolapsing towards the left atrium.

The chordae tendineae play an important role in maintaining the ventricular architecture and ensuring an efficient cardiac output [1,2]. It acts like a parachute cord that holds the leaflets at a high pressure to prevent blood from back-flowing towards the left atrium during systole. Hence, the chordae tendineae must have a high degree of elasticity, strength, and resistance to traction to support the heart of an average adult with an approximate load of 75 tons a day [1]. The chordae tendineae have been classified according to their site of insertion on the leaflets, yet their morphology and distribution on the leaflets result in a wide variety of distribution, form, and configuration for which there is no clear consensus on terminology [3].

Three types of chordae tendineae can be described according to their attachment on the leaflets. The (1) basal (or tertiary) chordae branch out from the papillary muscles 
and/or directly from the LV wall and are tied to the basal regions of the posterior leaflets; the (2) marginal (or primary) chordae are attached to the margin of the leaflets, and the space between the two marginal chordae is known to not exceed $3 \mathrm{~mm}$ with an attachment to the leaflet that is often bifurcated or trifurcated; and the (3) intermediary (or secondary) chordae extend from the papillary muscles and are attached to the LV side of the leaflets. The present study focuses on the intermediary chordae, which are also known as the strut chordae (SC).

In the anterior leaflets, the two thick and resistant SC are located originating in the medial aspect of the ventricular side of the leaflet and provide resistance to the leaflet at closing during systole to thus avoid a prolapse [4-6]. As the LV pressure increases, the tension along the SC raises rapidly, and the maximum SC tension value becomes three times larger than the surrounding chordae in the anterior leaflet [3,7,8]. Although the SC do not show much direct impact on leaflet coaptation, they play a vital role in creating a tunnel-shaped morphology of the MV throughout the cardiac cycle and maintaining MV function [5,9-11]. The large leaflet stress distribution over the anterior leaflet spreads from the fibrous trigone across the anterior central region towards the zone where the SC are connected [2,6,12]. All of these studies have emphasized the SC are critical to maintaining the long-term function of the MV.

Recent excellent studies have revealed diverse advancement in computational MV modeling, more specifically in terms of modeling of the chordae tendineae [13-16]. Moreover, solid mechanical evaluation of the chordae tissue and improved mathematical modeling of the chordae tendineae [17-21] as well as experimental and computational blood flow studies with respect to the chordae structure [22-24] have revealed the importance of chordae tendineae studies. However, there is still a lack of biomechanical information of the role of the SC; therefore, it is important to investigate the biomechanical effects of the insertion location of the SC in computational MV evaluations.

We employed our previously developed and validated computational MV modeling and evaluation protocols [25-31] to investigate the effect of varying the SC insertion location on normal MV function and dynamics to better understand the complex MV structures. Computational evaluations were conducted to assess the physiologic and biomechanical features of nine types of MVs with various insertion locations of the SC. Detailed information of the leaflet coaptation, stress distribution, coaptation length, coaptation angle, bulging height, and bulging distance with respect to the SC insertion location were investigated.

\section{Materials and Methods}

Figure 1 provides a brief demonstration of the virtual MV modeling and simulation procedures to assess the effect of altering the SC insertion location. A virtual parametric MV model was created to replicate a geometric 3D model for a normal human MV that can be easily transformed to investigate the effect of morphologic alteration by modifying several key geometric parameters. MATLAB (Mathworks Inc., Natick, MA, USA) was primarily utilized to produce the virtual parametric MVs and SC modeling, and ABAQUS (SIMULIA, Providence, RI, USA) was used to perform the computational simulations and evaluate the functional and biomechanical characteristics of MV function with respect to various insertion locations of the SC. A series of alterations were made in the SC insertion location for the parametric MVs, and computational simulations of MV function were performed to compare the MV models. 

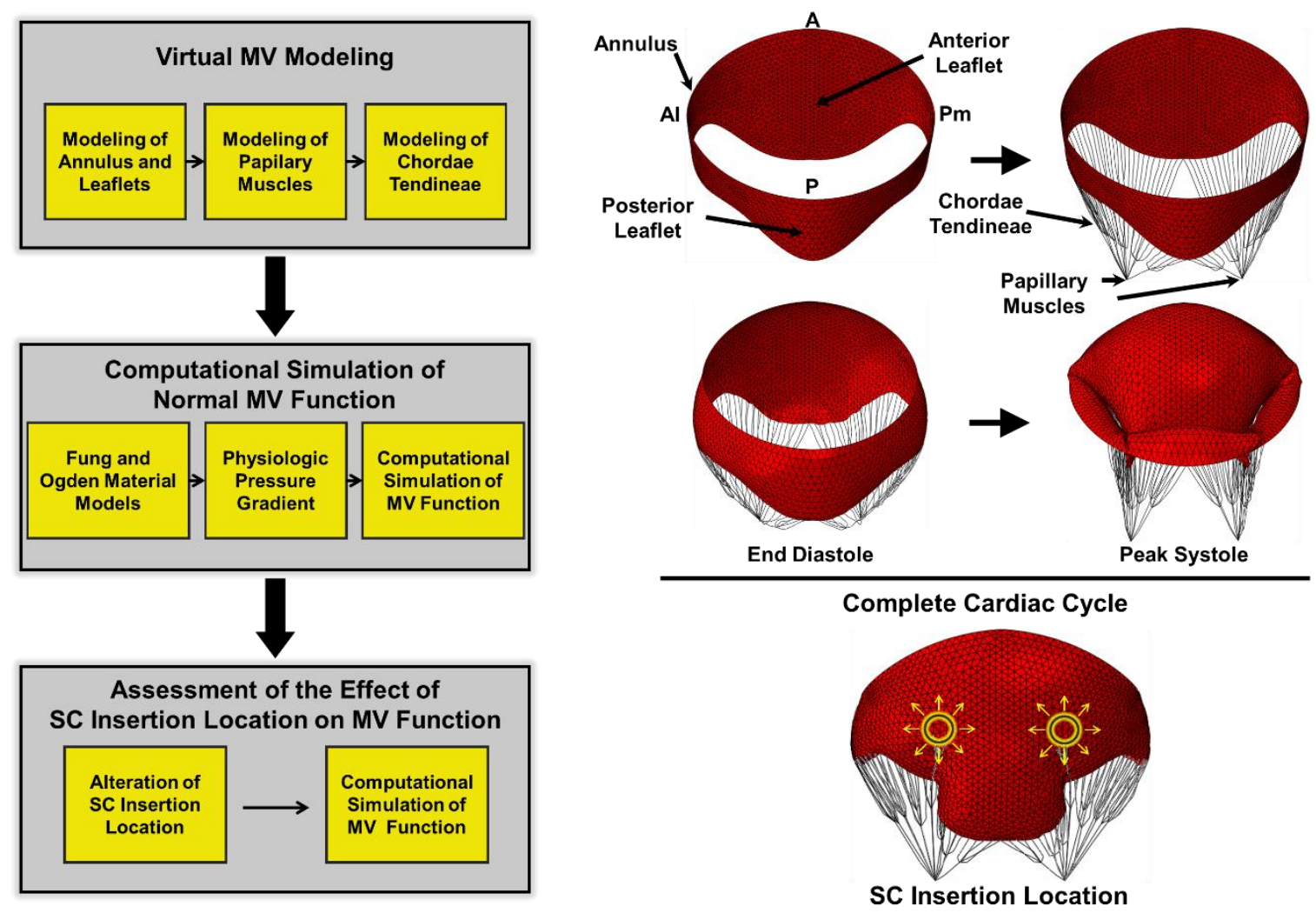

Figure 1. Study protocol for virtual parametric MV modeling and computational simulation of MV function to determine the effect of altering the SC insertion location. A-anterior; Al—anterolateral; $\mathrm{P}$-posterior; Pm-posteromedial.

\subsection{Virtual Parametric MV Modeling}

A normal parametric MV geometry at end diastole was designed to conduct a mechanistic study of the SC insertion location as described in our previous studies $[25,26]$. The representative structural dimensions of the mitral annulus, the anterior leaflet (a single cusp), the posterior leaflet (three cusps), the marginal chordae tendineae, and the papillary muscle tips were utilized in the present study. Briefly, the entire MV model was designed to be symmetric with respect to the center of the mitral orifice and aligned to the anteriorposterior (AP) plane of the annulus. The mitral annulus was created by implementing four primary landmark information with the cubic spline interpolation methods. The marginal leaflet boundary was created using a combination of sinusoidal functions, and a number of three-dimensional (3D) lines linking the mitral annulus and the free leaflet margin were constructed $[25,32]$. The non-uniform rational B-spline (NURBs) surface model was employed to generate a 3D surface model of the MV leaflets.

This MV leaflet model was meshed using triangular shell elements and imported into ABAQUS. The papillary muscle tips were placed $22 \mathrm{~mm}$ from the mid-annular plane positioning the two papillary muscle tips $24 \mathrm{~mm}$ apart to each other [33]. The marginal chordae tendineae were designed linking the leaflet free margin and the papillary muscle tips, and the chordal insertion was spread around the papillary muscle tips.

\subsection{SC Modeling and Alteration of SC Insertion Location}

The two SC were modeled by connecting the central region of the anterior leaflet (from the top portion of the rough zone to the medial portion of the atrial zone) and the papillary muscles [34]. The position of the SC is set as the ratio of the distance in the apical and lateral directions. Figure 2 presents the nine different SC insertion locations on the anterior leaflet. In the apical direction, the anterior leaflet centerline connecting the center point of the anterior annulus and anterior leaflet free margin served as reference for the position of the SC. With the center point of the free margin of the anterior leaflet set to 
zero, the center point of anterior annulus is set to one. The lateral location of the SC in the anterior view is set by the intercommissural line that connects the anterolateral (Al) and posteromedial $(\mathrm{Pm})$ points. The half point of the intercommissural line located on the anterior leaflet centerline was set to zero, and the Al and Pm points were set to one.

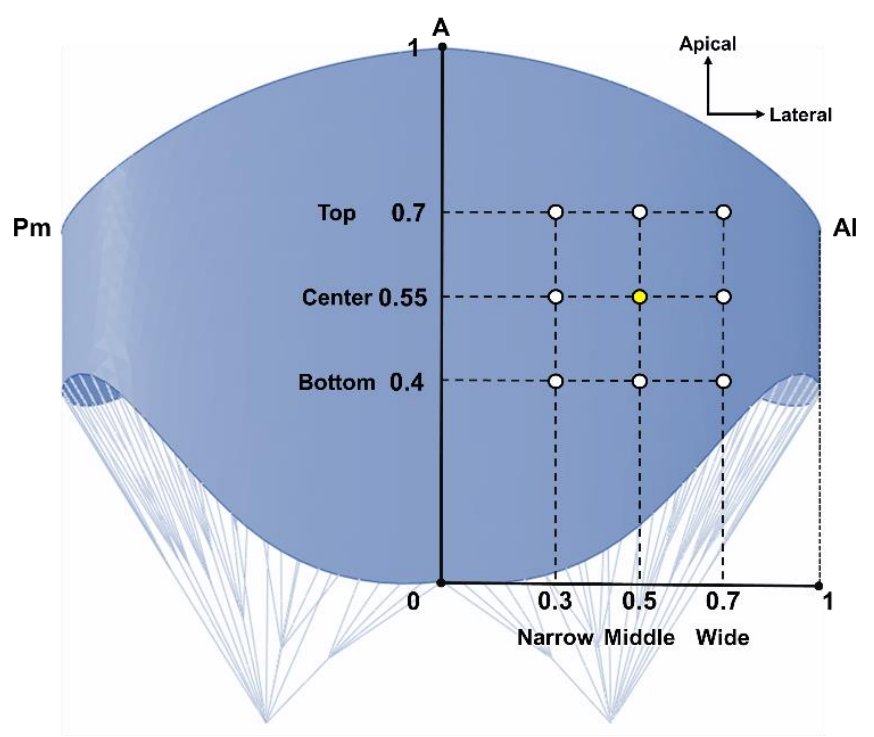

Figure 2. A schematic of anatomical alteration of the SC insertion location (anterior viewpoint). The yellow point indicates the normal SC insertion location. A-anterior; Al-anterolateral; Pm-posteromedial.

Several SC insertion locations were determined according to the ratio of the centerline of the anterior leaflet and half of the intercommissural line. All insertion locations of the SC were connected to the nearest node where the ratios were selected. The standard SC insertion location was set to the coordinates of 0.55 in the apical direction and 0.5 in the lateral direction. The displacement threshold for the SC insertion location (apical \pm 0.15 , lateral \pm 0.2 ) along each anatomical direction was determined according to the normal range of the SC insertion location based on previous clinical studies [35]. A total of nine MV modes were created from combinations of apical and lateral displacements of the SC insertion location. They are named as top, center, and bottom according to the ratios $(0.7$, 0.55 , and 0.4 ) in the apical direction and as narrow, middle, and wide at ratios of $0.3,0.5$, and 0.7 in the lateral direction. The SC lengths were determined according to the distance from the papillary muscle tips to the selected SC insertion nodes, with the shortest being $2.35 \mathrm{~cm}$ and the longest being $2.98 \mathrm{~cm}$. The altered SC insertion locations were implemented to the MV models, and the corresponding MV function was computationally analyzed using our dynamic finite element analysis protocol [25-27,31,32].

\subsection{Dynamic Finite Element Simulation of $M V$ Function}

The Ogden model was employed to define the nonlinear material behaviors of the marginal and SC tendineae. The cross-sectional areas of $0.29 \mathrm{~mm}^{2}$ and $0.27 \mathrm{~mm}^{2}$ were applied to the anterior and posterior marginal chordae, and $0.61 \mathrm{~mm}^{2}$ was set for the SC [36]. A Fung-type elastic material model was utilized to describe the anisotropic hyperelastic material behavior of the MV leaflets [31]. The principal material directions were defined along the circumferential $\left(\sigma_{c}\right)$ and radial $\left(\sigma_{t}\right)$ directions, and the material parameters of the anterior and posterior leaflet tissue were obtained from biaxial mechanical test data that were experimentally determined in a previous study [37]. The Fung-type elastic material model was then implemented in ABAQUS. The leaflet thicknesses of the anterior and posterior leaflets were set to 0.69 and $0.51 \mathrm{~mm}$, respectively [38]. The Poisson's ratio and density of the leaflets and chordae tissue were set to 0.48 and $1100 \mathrm{~kg} / \mathrm{m}^{3}$, respectively. A physiologic pressure gradient over the MV leaflet surface in the normal direction was 
incorporated throughout the full cardiac cycle. The maximum systolic ventricular pressure was $126 \mathrm{mmHg}(16.8 \mathrm{kPa})$ [39]. Specific contact interactions for leaflet-to-leaflet and leafletto-chordae with the friction coefficient of 0.05 were taken into consideration for leaflet coaptation [40]. Detailed protocols of our finite element MV evaluation are demonstrated in our previous studies [25-27,31,32].

\subsection{Evaluation of the Effect of the Alteration of SC Insertion Location}

Distributions of stress and coaptation across the leaflets over the full cardiac cycle were collected to investigate the effect of the different SC insertion locations. Biomechanical characteristics of the MV models at peak systole were evaluated. The structural and physiologic features of the MV models were qualitatively and quantitatively evaluated. Several geometric indices including coaptation length, coaptation angle, anterior bulging height at peak systole, and anterior leaflet bulging distance at end diastole were calculated and compared. The coaptation length refers to the distance between the free margin of the leaflet and the highest position of the leaflet coaptation. The anterior coaptation angle was defined by the angle between the A-P line and the line positioning between the anterior annular point and the highest position of the leaflet coaptation. The anterior bulging height indicates the distance between the A-P plane and the highest position of each leaflet toward the aorta. The anterior leaflet bulging distance was measured to evaluate how much blood flow was obstructed from the LV to the aorta during the diastole. The anterior leaflet bulging distance was determined using the length between the plane including the anterior annular point and two papillary muscles and the furthest anterior leaflet node.

\section{Results}

\subsection{Coaptation Distribution and Leaflet Stress Distribution}

Figure 3 demonstrates the MV configuration and MV leaflet contact distributions at peak systole from the anterior viewpoint. Nine MV models with different SC insertion locations were visualized and qualitatively compared. All nine MV models revealed appropriate leaflet coaptation while exhibiting the largest contact between the two leaflets in the center-narrow MV model. As the SC insertion location became wider, the contact distribution between the leaflets flattened more.

Figure 4 shows the leaflet stress distributions at peak systole of the MVs with nine different insertion locations of the SC from the atrial viewpoint. A threshold (at $0.4 \mathrm{MP}$ in red) of stress value was assigned to display the leaflet stress distributions so that larger stresses $(>0.4 \mathrm{MPa})$ than the threshold were presented in red while aiding in the comparison of the leaflet stress distributions among the MV models. As the SC insertion was located further toward the mitral annulus (apical) or wider (lateral), the leaflet stresses near the saddle-horn region of the anterior leaflet increased. The maximum stresses increased in accordance with the width of the SC insertion location (Figure 5). In all nine MV models, a similar stress distribution pattern was found in the anterior leaflet, demonstrating large stress values around the trigone region regardless of the differences in the SC insertion location. The top-narrow MV model showed the lowest maximum stress value, and the bottom-wide MV model revealed the largest maximum stress value. 


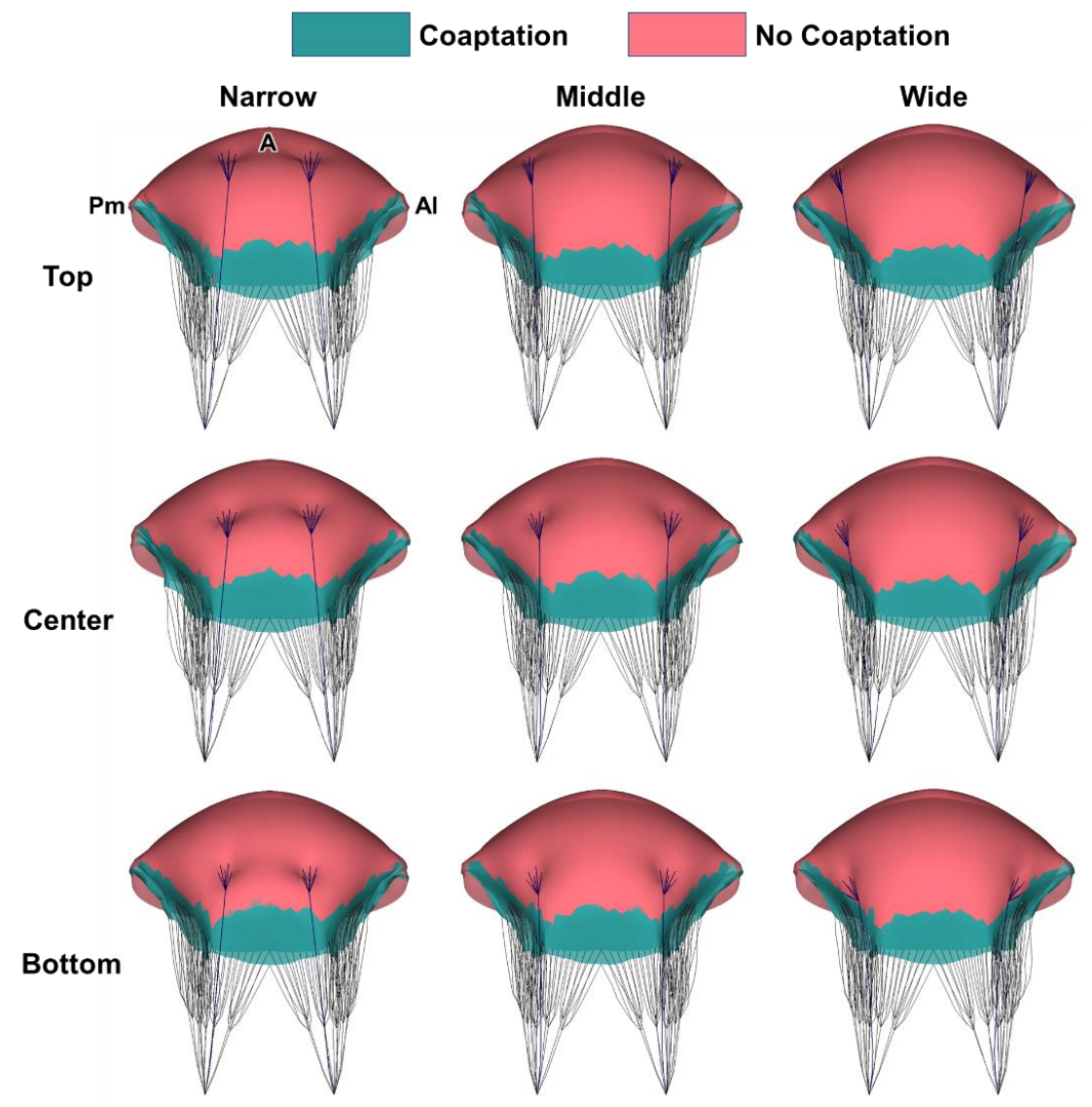

Figure 3. Leaflet coaptation distributions at peak systole with respect to alteration of the SC insertion location (anterior viewpoint). A—anterior; Al—anterolateral; Pm—posteromedial.

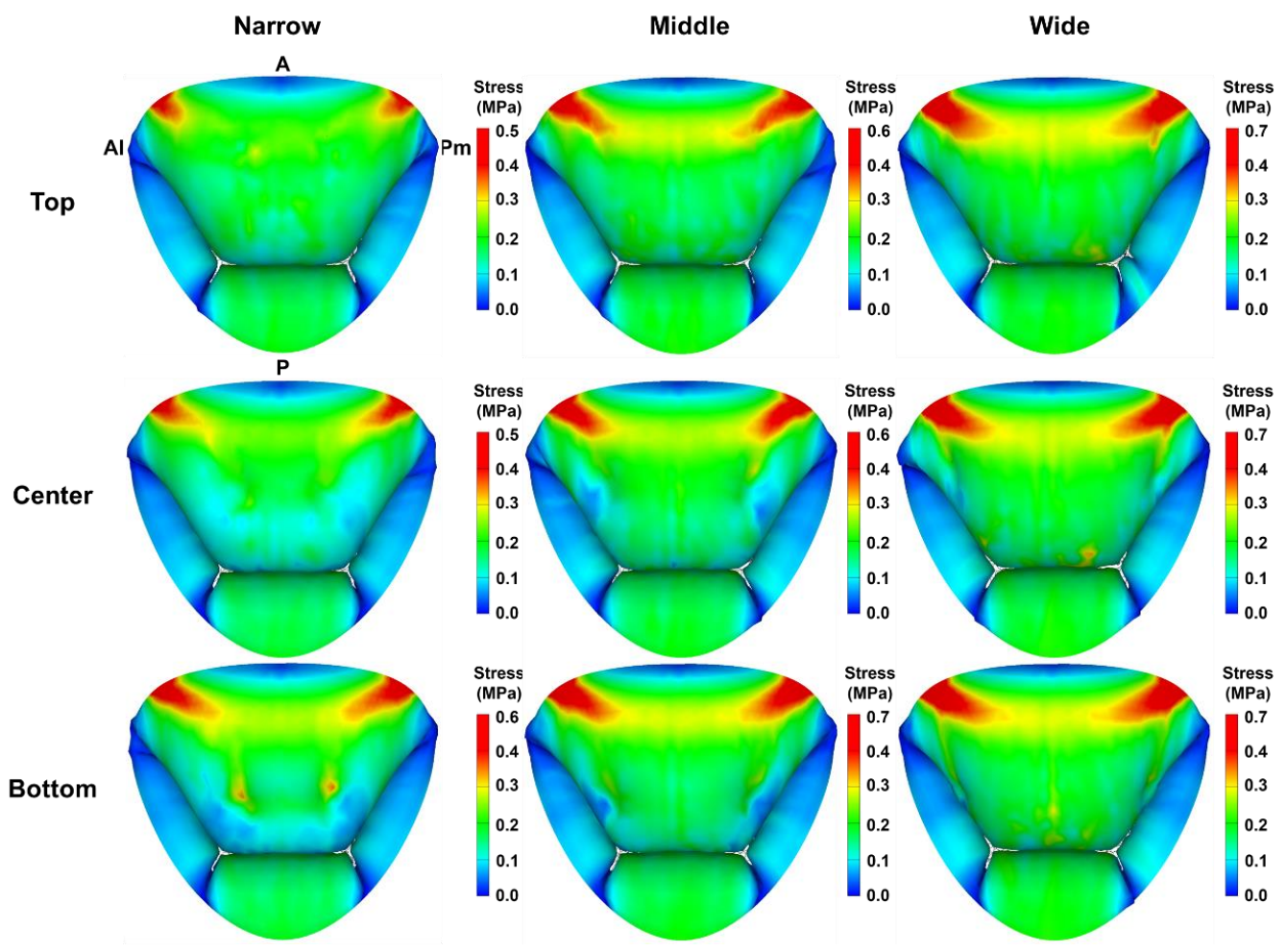

Figure 4. Stress distributions on the MV leaflets at peak systole with respect to alteration of the SC insertion location (atrial viewpoint). A-anterior; $\mathrm{Al}$-anterolateral; $\mathrm{P}$-posterior; $\mathrm{Pm}$-posteromedial. 


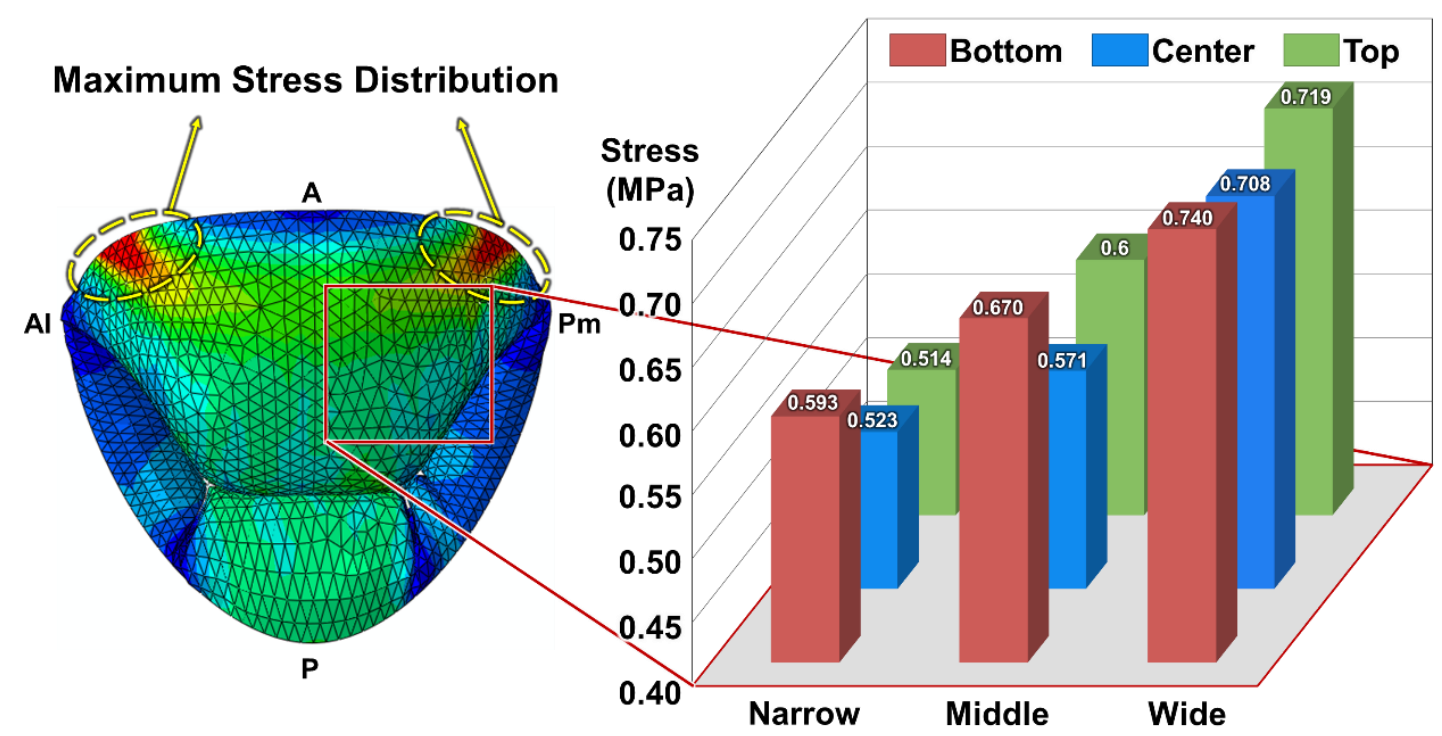

Figure 5. Maximum stress values in the annular trigone. The yellow circles represent the sites having the maximum stress values (atrial viewpoint). The red box indicates the leaflet region where the SC was inserted. A-anterior; Al—anterolateral; $\mathrm{P}$ - posterior; Pm-posteromedial.

\subsection{Leaflet Morphology and Mobility}

The morphologic features of the nine MV models with different SC insertion locations at peak systole were quantitated to assess the structure and mobility of the anterior leaflet (Figure 6). The cross-sectional views of the anteroposterior (A-P) leaflet edges are presented as blue (anterior leaflet) and red (posterior leaflet) lines to visualize and quantitate the coaptation lengths, coaptation angles, and anterior bulging heights. Dividing the nine MV models into three groups (top, center, and bottom), the center (narrow $=7.03 \mathrm{~mm}$, middle $=5.93 \mathrm{~mm}$, wide $=4.77 \mathrm{~mm}$ ) and bottom $($ narrow $=6.86 \mathrm{~mm}$, middle $=5.94 \mathrm{~mm}$, wide $=4.79 \mathrm{~mm}$ ) groups demonstrated decreased coaptation lengths in proportion to the width of the SC insertion location. The center and bottom groups also displayed an increase in coaptation angles in proportion to the width of the insertion location (center: narrow $=7.71^{\circ}$, middle $=8.63^{\circ}$, wide $=11.91^{\circ}$; bottom: narrow $=6.19^{\circ}$, middle $=8.66^{\circ}$, wide $=11.97^{\circ}$ ). In the top group, the middle and wide MV models showed similar coaptation lengths and coaptation angles (coaptation length: middle $=4.78 \mathrm{~mm}$, wide $=4.79 \mathrm{~mm}$; coaptation angle: middle $=11.91^{\circ}$, wide $\left.=12.09^{\circ}\right)$. The top-wide MV model demonstrated the greatest anterior bulging height $(4.13 \mathrm{~mm})$, and the bottom-middle MV model showed the minimum anterior bulging height $(3.88 \mathrm{~mm})$. In the wide group, all three MV models had similar bulging heights (top $=4.13 \mathrm{~mm}$, center $=4.09 \mathrm{~mm}$, bottom $=4.1 \mathrm{~mm}$ ). In the middle group, the bulging heights decreased markedly when the SC insertion location moved from the top to the middle and bottom.

\subsection{Anterior Leaflet Bulging Distance}

The anterior leaflet bulging distances of the nine MV models with different types of SC insertion location at end diastole are shown in Figure 7. While similar bulging distances were observed in eight MV models (11.12-11.42 $\mathrm{mm}$ ), a much smaller bulging distance was found in the top-narrow MV model $(0.74 \mathrm{~mm})$. 

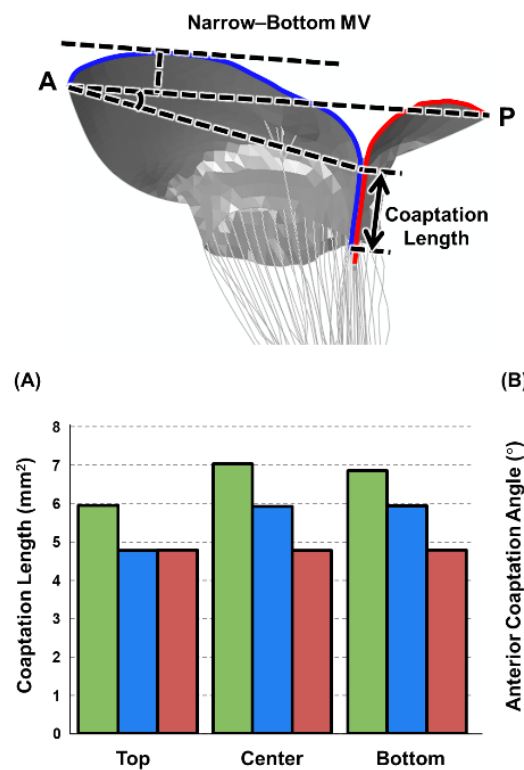

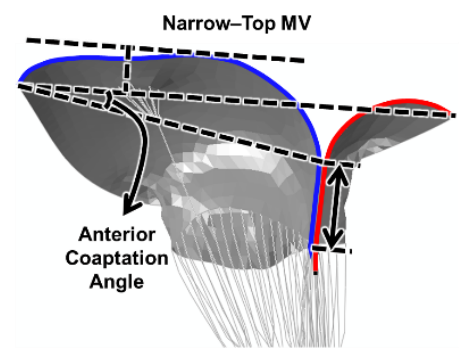

(B)

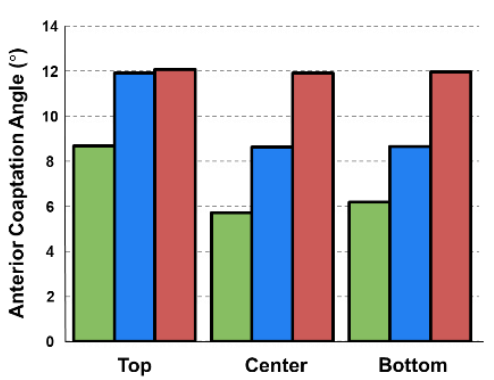

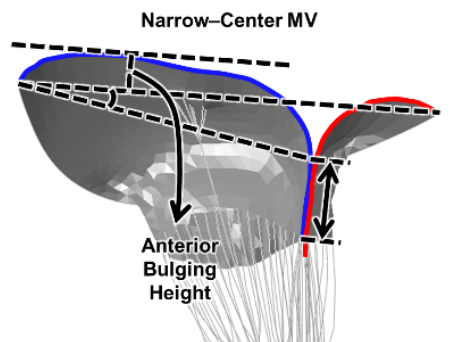
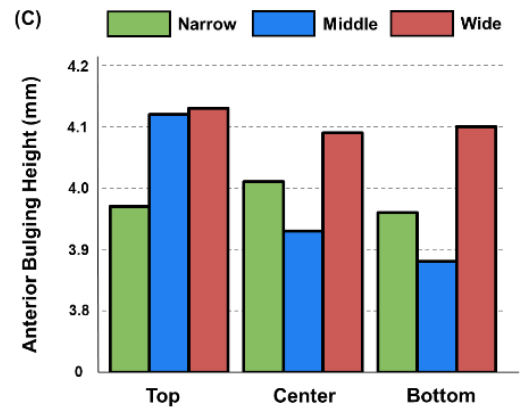

Figure 6. Morphologic features and quantitative assessment of the MV leaflets at peak systole. For the narrow MV group, the cross-sectional views of the A2-P2 leaflet edges are presented in blue (anterior leaflet) and red (posterior leaflet) lines. Quantitative morphologic assessment includes (A) coaptation lengths, (B) coaptation angles, and (C) anterior bulging heights. A-anterior; $\mathrm{P}$-posterior.
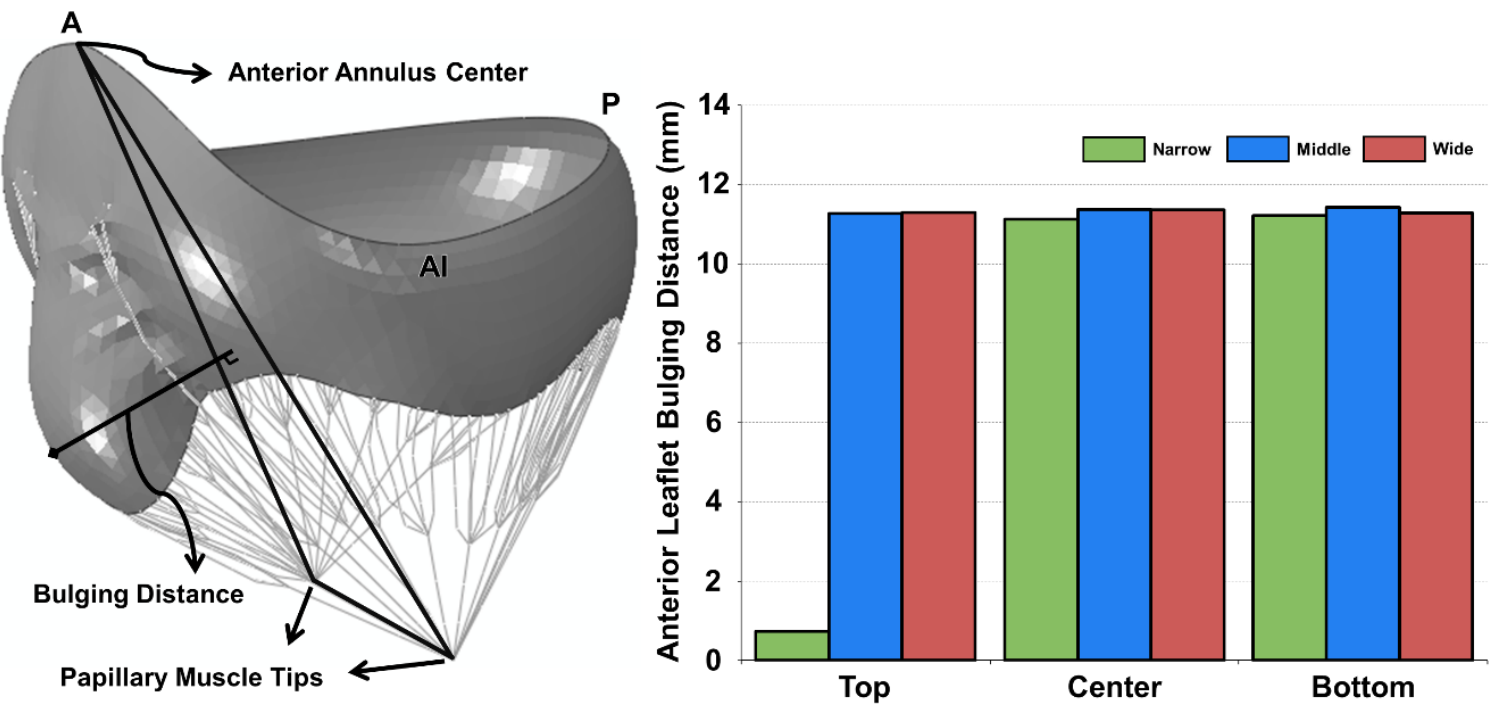

Figure 7. Anterior leaflet bulging distance with respect to alteration of the SC insertion location during the diastolic phase. The shortest distance is found in the narrow-top MV model. A-anterior; Al—anterolateral; $\mathrm{P}$ - posterior.

\section{Discussion}

Two tendon-like SCs, particularly strong and thick, are inserted in a fanlike manner into the ventricular side of the anterior MV leaflet and stretched toward the annulus. The importance of the roles of the SC in maintaining an appropriate anatomical valvular shape is obviously inferred from their anatomical location and bigger size when compared to other chordae. The SC endure tensional stresses three times larger than the marginal chordae but do not affect the existence of mitral regurgitation. Removing the SC tethering would cause the central region of the anterior leaflet to extend further towards the mitral annulus, resulting in flexible leaflet tissue around the coaptating leaflet margin [6,34]. In the present study, we utilized parametric MV modeling and finite element simulation to evaluate the biomechanics and function of the anatomical alteration of the SC insertion location based on clinical data. 
Alteration of the SC insertion location demonstrated the smallest maximum leaflet stress $(0.514 \mathrm{MPa})$ in the top-narrow $\mathrm{MV}$ model and the largest maximum leaflet stress $(0.740 \mathrm{MPa})$ in the bottom-wide MV model at peak systole (Figures 4 and 5). The overall pattern of leaflet stress distribution was similar for all nine MV models, and large stresses near the anterior annular saddle-horn region increased in proportion to the width of the $\mathrm{SC}$ insertion location. In all nine MV models, the maximum stresses were found in the anterior annular trigone region. It is speculated that a wide width of the SC insertion location would not provide the central area of the anterior leaflet with sufficient tensional support, resulting in increased leaflet stresses near the anterior annular saddle-horn region. In addition, the maximum stress value was found to decrease as the SC insertion location was close to the mitral annulus. With the SC insertion location close to the annulus, the anterior leaflet displayed more leaflet bulging, indicating increased stresses in the central and marginal zone of the anterior leaflet. As the SC can maintain three times larger chordal stresses than the marginal chordae, lower leaflet stress values were observed in the region from the central to marginal zone when the SC was inserted far from the mitral annulus, reducing a considerable amount of overall leaflet stresses in the zone.

Consistent with previous studies suggesting that the presence of the SC does not affect coaptation, all nine MV models exhibited full coaptation and similar leaflet contact distribution (Figure 3). The MV models with a wider SC insertion location displayed further spread distribution of leaflet coaptation. A narrower SC insertion location resulted in a longer coaptation length and hence a smaller anterior coaptation angle (Figure 6). In the center and bottom groups, as the width increased, the coaptation length decreased proportionally while the coaptation angle increased. However, in the top group, the middle and wide MV models revealed similar values of the coaptation length and anterior coaptation angle. In the wide group, all three locations along the apical direction showed comparable coaptation lengths, anterior coaptation angles, and anterior bulging heights. Particularly in the wide group, little difference was found in the leaflet stress and contact distributions (coaptation length and coaptation angle) as well as the anterior bulging height and bulging distance.

The anterior leaflet bulging distance indicates how the SC influence the blood outflow from the left ventricle. Systolic anterior motion (SAM) refers to the clinical observation such that the distal portion of the anterior leaflet is placed obstructing the left ventricular outflow area. When the SC restrict the anterior leaflet mobility, SAM can occur [6]. The SC prevent the lateral portion of the anterior leaflet from bulging toward the left ventricular outflow tract (LVOT) by acting like a sail. The top-narrow MV model demonstrated the shortest anterior leaflet bulging distance, indicating that the SC prevent the entire anterior leaflet bulging toward the LVOT to develop an orifice area at diastole smaller than the others (Figure 7). The top-narrow MV model also showed lower stresses across the anterior leaflet (Figure 4) and the lowest maximum stresses (Figure 5). Therefore, in principle, this topnarrow MC model could be assumed to have the most suitable SC insertion location from the valvular functional perspective. However, in the case of functional mitral regurgitation accompanied by distal displacement of the papillary muscles, the tethering force in the SC increases; this could result in tenting and regurgitation [35].

The parametric MV modeling strategy employed in the present study has several limitations. Although recent studies demonstrated and emphasized the importance of patient-specific chordae modeling [41-43], true geometric configurations of the complete chordae tendineae structure are still not available from 3D echocardiographic data due to the restricted spatial and temporal resolution issue of the currently available clinical imaging modality. The parametric MV model was created based on the average dimensions of normal human MVs. The key focus of the present study is to evaluate the effect of varying the SC insertion location on normal MV function and dynamics to better understand the complex MV structures from the biomechanical perspectives. The length of the SC is not directly configured but determined by quantitating the distance between the papillary muscle tips and the locations where the SC were inserted in this study. Therefore, the 
simulated variations of the SC insertion location may not implement directly on evaluation of patient MV models. Nevertheless, valuable information can be obtained from assessing the relative dimensional comparisons of these MV apparatus deformations to better understand the effect of the SC insertion locations on MV function.

\section{Conclusions}

We conducted computational evaluations to examine the effect of the SC insertion location on the function and dynamics a normal MV. Alterations of the SC insertion locations demonstrated differences in the biomechanical measurements and functional indices throughout the cardiac cycle. The SC have a unique structure and play a key role in reinforcing the tunnel-shape of the MV throughout the cardiac cycle and ensuring mobility of the anterior leaflet. While the leaflet stress distribution and coaptation showed similar patterns in all nine MV models, the maximum leaflet stresses increased in accordance with the width of the SC insertion locations. This computational MV evaluation can aid in understanding the effect of the SC insertion locations on mechanism, function, and pathophysiology of the MV.

Author Contributions: Conceptualization,W.H. and H.K.; methodology,W.H. and S.J.; validation, W.H. and S.J.; investigation, W.H., S.J., M.K. and H.H.K.; resources, H.K.; writing-original draft preparation, W.H.; writing-review and editing, H.K.; visualization, M.K. and H.H.K.; supervision, H.K. All authors have read and agreed to the published version of the manuscript.

Funding: This research was supported by the National Research Foundation of Korea (NRF) through the Ministry of Science and ICT (NRF-2019R1A2C1005094).

Institutional Review Board Statement: Not applicable.

Informed Consent Statement: Not applicable.

Data Availability Statement: The datasets generated during this study are available from the corresponding author on reasonable request.

Conflicts of Interest: The authors declare no conflict of interest.

\section{References}

1. Mestres, C.A.; Bernal, J.M. Mitral valve repair: The chordae tendineae. J. Tehran Heart Cent. 2012, 7, 92-99.

2. Chen, L.; Yin, F.C.; May-Newman, K. The structure and mechanical properties of the mitral valve leaflet-strut chordae transition zone. J. Biomech. Eng. 2004, 126, 244-251. [CrossRef]

3. Degandt, A.A.; Weber, P.A.; Saber, H.A.; Duran, C.M. Mitral valve basal chordae: Comparative anatomy and terminology. Ann. Thorac. Surg. 2007, 84, 1250-1255. [CrossRef]

4. Goetz, W.A.; Lim, H.S.; Lansac, E.; Saber, H.A.; Pekar, F.; Weber, P.A.; Duran, C.M. Anterior mitral basal 'stay' chords are essential for left ventricular geometry and function. J. Heart Valve Dis. 2005, 14, 195-202. [PubMed]

5. Goetz, W.A.; Lim, H.S.; Pekar, F.; Saber, H.A.; Weber, P.A.; Lansac, E.; Birnbaum, D.E.; Duran, C.M. Anterior mitral leaflet mobility is limited by the basal stay chords. Circulation 2003, 107, 2969-2974. [CrossRef] [PubMed]

6. Chen, L.; May-Newman, K. Effect of strut chordae transection on mitral valve leaflet biomechanics. Ann. Biomed. Eng. 2006, 34, 917-926. [CrossRef] [PubMed]

7. Marcus, R.H.; Sareli, P.; Pocock, W.A.; Meyer, T.E.; Magalhaes, M.P.; Grieve, T.; Antunes, M.J.; Barlow, J.B. Functional anatomy of severe mitral regurgitation in active rheumatic carditis. Am. J. Cardiol. 1989, 63, 577-584. [CrossRef]

8. van Rijk-Zwikker, G.L.; Delemarre, B.J.; Huysmans, H.A. Mitral valve anatomy and morphology: Relevance to mitral valve replacement and valve reconstruction. J. Card. Surg. 1994, 9, 255-261. [CrossRef]

9. Obadia, J.F.; Casali, C.; Chassignolle, J.F.; Janier, M. Mitral subvalvular apparatus: Different functions of primary and secondary chordae. Circulation 1997, 96, 3124-3128. [CrossRef] [PubMed]

10. Obadia, J.F.; Janier, M. Second order anterior mitral leaflets play a role in preventing systolic anterior motion. Ann. Thorac. Surg. 2002, 73, 1689-1690. [CrossRef]

11. Kunzelman, K.S.; Cochran, R.P.; Chuong, C.; Ring, W.S.; Verrier, E.D.; Eberhart, R.D. Finite element analysis of the mitral valve. J. Heart Valve Dis. 1993, 2, 326-340. [PubMed]

12. Padala, M.; Gyoneva, L.; Yoganathan, A.P. Effect of anterior strut chordal transection on the force distribution on the marginal chordae of the mitral valve. J. Thorac. Cardiovasc. Surg. 2012, 144, 624-633.e2. [CrossRef]

13. Feng, L.; Qi, N.; Gao, H.; Sun, W.; Vazquez, M.; Griffith, B.E.; Luo, X. On the chordae structure and dynamic behaviour of the mitral valve. IMA J. Appl. Math. 2018, 83, 1066-1091. [CrossRef] 
14. Khalighi, A.H.; Rego, B.V.; Drach, A.; Gorman, R.C.; Gorman, J.H., 3rd; Sacks, M.S. Development of a functionally equivalent model of the mitral valve chordae tendineae through topology optimization. Ann. Biomed. Eng. 2019, 47, 60-74. [CrossRef]

15. Panicheva, D.; Villard, P.F.; Hammer, P.E.; Perrin, D.; Berger, M.O. Automatic extraction of the mitral valve chordae geometry for biomechanical simulation. Int. J. Comput. Assist. Radiol Surg. 2021, 16, 709-720. [CrossRef]

16. Marom, G.; Plitman Mayo, R.; Again, N.; Raanani, E. Numerical biomechanics models of the interaction between a novel transcatheter mitral valve device and the subvalvular apparatus. Innovations 2021, 1556984521999362, Online ahead of print.

17. Chen, S.; Sari, C.R.; Gao, H.; Lei, Y.; Segers, P.; De Beule, M.; Wang, G.; Ma, X. Mechanical and morphometric study of mitral valve chordae tendineae and related papillary muscle. J. Mech. Behav. Biomed. Mater. 2020, 111, 104011. [CrossRef] [PubMed]

18. Kaiser, A.D.; McQueen, D.M.; Peskin, C.S. Modeling the mitral valve. Int. J. Numer. Method. Biomed. Eng. 2019, 35, e3240. [CrossRef]

19. Paulsen, M.J.; Imbrie-Moore, A.M.; Wang, H.; Bae, J.H.; Hironaka, C.E.; Farry, J.M.; Lucian, H.J.; Thakore, A.D.; MacArthur, J.W.; Cutkosky, M.R.; et al. Mitral chordae tendineae force profile characterization using a posterior ventricular anchoring neochordal repair model for mitral regurgitation in a three-dimensional-printed ex vivo left heart simulator. Eur. J. Cardiothorac. Surg. 2020 57, 535-544. [CrossRef]

20. Ross, C.J.; Laurence, D.W.; Hsu, M.C.; Baumwart, R.; Zhao, Y.D.; Mir, A.; Burkhart, H.M.; Holzapfel, G.A.; Wu, Y.; Lee, C.H. Mechanics of porcine heart valves' strut chordae tendineae investigated as a leaflet-chordae-papillary muscle entity. Ann. Biomed. Eng. 2020, 48, 1463-1474. [CrossRef] [PubMed]

21. Shen, X.; Wang, T.; Cao, X.; Cai, L. The geometric model of the human mitral valve. PLoS ONE 2017, 12, e0183362. [CrossRef]

22. Meschini, V.; de Tullio, M.D.; Verzicco, R. Effects of mitral chordae tendineae on the flow in the left heart ventricle. Eur. Phys. J. E Soft Matter 2018, 41, 27. [CrossRef]

23. Papolla, C.; Darwish, A.; Kadem, L.; Rieu, R. Impact of mitral regurgitation on the flow in a model of a left ventricle. Cardiovasc. Eng. Technol. 2020, 11, 708-718. [CrossRef] [PubMed]

24. Toma, M.; Einstein, D.R.; Bloodworth, C.H.t.; Cochran, R.P.; Yoganathan, A.P.; Kunzelman, K.S. Fluid-structure interaction and structural analyses using a comprehensive mitral valve model with 3d chordal structure. Int. J. Numer. Method. Biomed. Eng. 2017, 33, e2815. [CrossRef]

25. Choi, A.; McPherson, D.D.; Kim, H. Biomechanical evaluation of the pathophysiologic developmental mechanisms of mitral valve prolapse: Effect of valvular morphologic alteration. Med. Biol. Eng. Comput. 2016, 54, 799-809. [CrossRef]

26. Choi, A.; McPherson, D.D.; Kim, H. Neochordoplasty versus leaflet resection for ruptured mitral chordae treatment: Virtual mitral valve repair. Comput. Biol. Med. 2017, 90, 50-58. [CrossRef]

27. Choi, A.; McPherson, D.D.; Kim, H. Computational virtual evaluation of the effect of annuloplasty ring shape. Int. J. Numer. Method. Biomed. Eng. 2017, 33, e2831. [CrossRef] [PubMed]

28. Rim, Y.; Chandran, K.B.; Laing, S.T.; Kee, P.; McPherson, D.D.; Kim, H. Can computational simulation quantitatively determine mitral valve abnormalities? JACC Cardiovasc. Imaging 2015, 8, 1112-1114. [CrossRef] [PubMed]

29. Rim, Y.; Choi, A.; Laing, S.T.; McPherson, D.D.; Kim, H. Three-dimensional echocardiography-based prediction of posterior leaflet resection. Echocardiography 2014, 31, E300-E303. [CrossRef]

30. Rim, Y.; Laing, S.T.; Kee, P.; McPherson, D.D.; Kim, H. Evaluation of mitral valve dynamics. JACC Cardiovasc. Imaging 2013, 6, 263-268. [CrossRef]

31. Rim, Y.; McPherson, D.D.; Chandran, K.B.; Kim, H. The effect of patient-specific annular motion on dynamic simulation of mitral valve function. J. Biomech. 2013, 46, 1104-1112. [CrossRef] [PubMed]

32. Rim, Y.; Choi, A.; McPherson, D.D.; Kim, H. Personalized computational modeling of mitral valve prolapse: Virtual leaflet resection. PLoS ONE 2015, 10, e0130906. [CrossRef] [PubMed]

33. Sonne, C.; Sugeng, L.; Watanabe, N.; Weinert, L.; Saito, K.; Tsukiji, M.; Yoshida, K.; Takeuchi, M.; Mor-Avi, V.; Lang, R.M. Age and body surface area dependency of mitral valve and papillary apparatus parameters: Assessment by real-time three-dimensional echocardiography. Eur. J. Echocardiogr. 2009, 10, 287-294. [CrossRef] [PubMed]

34. Lam, J.H.; Ranganathan, N.; Wigle, E.D.; Silver, M.D. Morphology of the human mitral valve. I. Chordae tendineae: A new classification. Circulation 1970, 41, 449-458. [CrossRef] [PubMed]

35. Song, J.M.; Kim, J.J.; Ha, T.Y.; Lee, J.W.; Jung, S.H.; Hwang, I.S.; Lee, I.; Sun, B.J.; Kim, D.H.; Kang, D.H.; et al. Basal chordae sites on the mitral valve determine the severity of secondary mitral regurgitation. Heart 2015, 101, 1024-1031. [CrossRef]

36. Prot, V.; Skallerud, B.; Sommer, G.; Holzapfel, G.A. On modelling and analysis of healthy and pathological human mitral valves: Two case studies. J. Mech. Behav. Biomed. Mater. 2010, 3, 167-177. [CrossRef]

37. May-Newman, K.; Yin, F.C. A constitutive law for mitral valve tissue. J. Biomech. Eng. 1998, 120, 38-47. [CrossRef]

38. May-Newman, K.; Yin, F.C. Biaxial mechanical behavior of excised porcine mitral valve leaflets. Am. J. Physiol. 1995, 269, H1319-H1327. [CrossRef]

39. Mitchell, J.R.; Wang, J.J. Expanding application of the wiggers diagram to teach cardiovascular physiology. Adv. Physiol. Educ. 2014, 38, 170-175. [CrossRef]

40. Stevanella, M.; Votta, E.; Redaelli, A. Mitral valve finite element modeling: Implications of tissues' nonlinear response and annular motion. J. Biomech. Eng. 2009, 131, 121010. [CrossRef]

41. Khalighi, A.H.; Drach, A.; Bloodworth, C.H.; Pierce, E.L.; Yoganathan, A.P.; Gorman, R.C.; Gorman, J.H., 3rd; Sacks, M.S. Mitral valve chordae tendineae: Topological and geometrical characterization. Ann. Biomed. Eng. 2017, 45, 378-393. [CrossRef] [PubMed] 
42. Sacks, M.; Drach, A.; Lee, C.H.; Khalighi, A.; Rego, B.; Zhang, W.; Ayoub, S.; Yoganathan, A.; Gorman, R.C.; Gorman Iii, J.H. On the simulation of mitral valve function in health, disease, and treatment. J. Biomech. Eng. 2019, 141, 0708041. [CrossRef] [PubMed]

43. Zuo, K.; Pham, T.; Li, K.; Martin, C.; He, Z.; Sun, W. Characterization of biomechanical properties of aged human and ovine mitral valve chordae tendineae. J. Mech. Behav. Biomed. Mater. 2016, 62, 607-618. [CrossRef] [PubMed] 